\title{
Cryptosporidium infections in sheep farms from Italy
}

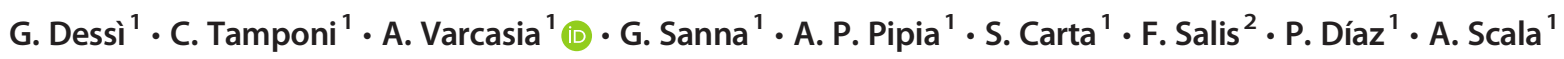

Received: 12 August 2020 / Accepted: 25 October 2020 / Published online: 3 November 2020

(C) The Author(s) 2020

\begin{abstract}
Cryptosporidiosis is recognized as being a significant cause of gastrointestinal illness due to its wide range of vertebrate hosts, including humans. Infection with Cryptosporidium spp. is especially common in young domestic ruminants (calves, lambs and goat kids) and has been associated with economic losses worldwide. In contrast to cattle, to date, detailed studies on Cryptosporidium infections in sheep from Europe are still limited; thus, their importance as reservoirs of Cryptosporidium species with implications on animal and public health still needs to be clarified. This study evaluates the prevalence and zoonotic potential of Cryptosporidium spp. in sheep farms in Italy. A total of 915 individual faecal samples divided into three different animal categories were collected from 61 sheep farms. Each sample was examined by microscopy of faecal smears stained by modified Ziehl-Neelsen and by biomolecular techniques. Cryptosporidium oocysts were detected in $10.1 \%$ of the animals examined and in $34.4 \%$ of the farms. The prevalence of Cryptosporidium spp. was significantly higher $\left(\chi^{2}=51.854 ; P<\right.$ 0.001 ) in diarrhoeic samples than in pasty or normal faeces. Genotype analyses showed the presence of two Cryptosporidium species: C. parvum and C. ubiquitum. Subtyping analysis of C. parvum isolates revealed the presence of subtypes IIa15G2R1 and IIdA20G1 and of subtype XIIa for C. ubiquitum. These findings have public health implications since both Cryptosporidium species identified are considered zoonotic, and C. parvum is the second-most common Cryptosporidium species infecting humans. Our data reveal that lambs, especially those excreting diarrhoeic faeces, may be important reservoirs of Cryptosporidium. We also highlight the need to establish adequate control and monitoring programmes for the control of this infection in sheep farms primarily through coprological monitoring.
\end{abstract}

Keywords Cryptosporidium $\cdot$ Lambs $\cdot$ Sheep $\cdot$ Zoonosis $\cdot$ Italy

\section{Introduction}

Cryptosporidiosis is a global disease caused by apicomplexan parasites belonging to the genus Cryptosporidium, which are recognized as a significant source of gastrointestinal illness for a wide range of vertebrate hosts, including humans (Xiao, 2010, Ryan et al., 2016). Molecular investigations have

G. Dessì and C. Tamponi contributed equally to this work.

Section Editor: Yaoyu Feng

A. Varcasia

varcasia@uniss.it

1 Laboratory of Parasitology, Veterinary Teaching Hospital, Department of Veterinary Medicine, University of Sassari, Parassitologia Veterinaria, Via Vienna 2, 07100 Sassari, Italy

2 Investigation in Animal Health: Galicia (INVESAGA Group), School of Veterinary Medicine, Universidad de Santiago de Compostela, Lugo, Spain identified nearly 40 species and over 50 genotypes, of which Cryptosporidium hominis and Cryptosporidium parvum are the most prevalent in humans, causing asymptomatic or mild-to-severe gastrointestinal diseases (Ryan et al., 2014, Feng et al., 2018, Firoozi et al., 2019, Roellig and Xiao, 2020).

Among livestock, ruminants are considered to be important reservoirs of both host-specific and zoonotic Cryptosporidium species as they shed a large number of oocysts that cause environmental contamination (Xiao, 2010, Santin, 2020). In particular, cattle have been considered a health risk to humans due to the potential source of cryptosporidiosis (Santin, 2020).

However, little is known about the disease and there are contrasting opinions about the transmission route and the role played by different animal species, such as sheep and goats, in the epidemiology of human infections (Ryan et al., 2005, Broglia et al. 2008, Xiao, 2010, Cacciò et al., 2013). Nevertheless, sheep and/or goats appear to harbour zoonotic species or genotypes of the protozoan, suggesting that sheep and/or goats should be considered as epidemiologically 
significant reservoirs (Geurden et al., 2008, Mueller-Doblies et al., 2008, Quilez et al., 2008).

Cryptosporidium infections, due primarily to zoonotic C. parvum, are especially common in young domestic ruminants (calves, lambs and goat kids) and are associated with economic losses due to the cost of veterinary care and the clinical symptoms including diarrhoea, dehydration, delayed growth and weight loss, often leading to death (CastroHermida et al., 2002, Ye et al., 2013, Mammeri et al., 2019, Hatam-Nahavandi et al., 2019, Santin, 2020).

Sheep can be infected with a number of Cryptosporidium species. Of these, C. parvum, C. xiaoi and C. ubiquitum are the most common, while $C$. hominis, $C$. andersoni, $C$. bovis, C. scrofarum, C. suis, C. fayeri and C. canis have been sporadically reported (Pritchard et al., 2008, Paraud and Chartier, 2012, Koinari et al., 2014, Squire et al., 2017, Díaz et al., 2010, 2015, 2018a, Zhang et al., 2018).

The presence of Cryptosporidium spp. in sheep worldwide shows variations in the prevalence related to factors such as the age and health of the sheep. In healthy animals, for example, lower prevalence rates $(0.9$ to $14.3 \%)$ have been reported in adult sheep (Li et al., 2016, Díaz et al., 2018a,; Holsback et al., 2018, Qi et al., 2019) than in lambs (6.0\% to 20.3\%) (Díaz et al., 2018a; Majeed et al., 2018; Holsback et al., 2018). However, the highest percentages of infection have been recorded in lambs with diarrhoea, showing prevalences ranging from 24.16 to $100 \%$ (Papanikolopoulou et al., 2018, Mammeri et al., 2019, Rabee et al., 2020).

In Italy, Cryptosporidium spp. have been reported in humans (Cacciò et al., 2013) and in domestic animals such as dogs (Cervone et al., 2019), cats (Sauda et al., 2019), horses (Lanci et al., 2018) and cattle (Díaz et al., 2018b). However, data on Cryptosporidium infections in sheep in Italy are limited to a single survey carried out in Abruzzo, Central Italy, which reported that $17.45 \%$ of lambs were seropositive to Cryptosporidium (Paoletti et al., 2009). Despite the lack of data on the spread of Cryptosporidium infection in sheep in Italy, lambs have been identified as a source of zoonotic transmission to humans (Cacciò et al., 2013).

Unlike for cattle, detailed studies on Cryptosporidium infections in sheep in Europe are still limited, and the majority of data concern the prevalence in diarrhoeic lambs (Quílez et al., 2008, Pritchard et al., 2008, Paoletti et al., 2009, Cacciò et al., 2013, Díaz et al., 2010, 2015). However, there are few data on the occurrence of this protozoan in healthy sheep, especially post-weaned and adults; thus, their importance as reservoirs of Cryptosporidium species with implications for animal and public health still needs to be clarified.

Sardinia hosts $45 \%$ of the entire sheep stock in Italy and almost $4 \%$ of the European sheep population (Varcasia et al., 2020). One recent study reported a prevalence of $38.8 \%$ for Cryptosporidium spp. in calves in Sardinia (Díaz et al., 2018b). The present study contributes to global knowledge on Cryptosporidium infections in sheep, by evaluating the prevalence and zoonotic potential of Cryptosporidium spp. in sheep farms in Italy.

\section{Material and methods}

\section{Sample collection and microscopic analysis}

From November 2015 to February 2016, a total of 61 sheep farms located in the four provinces of Sardinia (Cagliari, Sassari, Oristano, Nuoro) were investigated, and a total of 915 individual faecal samples were collected. All the farms selected adopt a semi-intensive management system (pasture or range grazing, supplementary feeding mainly on commercial and/or cereal fodder) and no artificial suckling of lambs; both sheep and lambs share the same night shelter during the lambing season. A total of 15 samples from each flock were collected.

Five samples from each animal group were collected as follows: lambs aged 5-30 days (group 1), sheep from parturition to 30 days (group 2) and sheep within the 30 days before parturition (group 3). After collection from the rectum, each faecal sample was macroscopically examined to establish the faecal consistency, which was classified as normal (wellformed faeces), pasty (soft, not well formed) or diarrhoeic (liquid faeces). Faecal samples were also checked for the presence of mucus or blood.

Samples were then transported in a cool box to the Parasitology Laboratory at the Veterinary Teaching Hospital of the University of Sassari, Italy, and then stored at $4{ }^{\circ} \mathrm{C}$ until examination within $24 \mathrm{~h}$ of collection. Faecal samples were then examined for the presence of Cryptosporidium spp. oocysts by microscopy of faecal smears stained using the modified Ziehl-Neelsen technique according to Angus (1987). The intensity of oocyst shedding was evaluated semiquantitatively according to the average number of oocysts in 10 fields at $\times 400$ magnification, expressed as oocysts per field (OPF) as described by Castro-Hermida et al. (2002). The mean intensity (MI) was calculated considering the OPF arithmetic average of the total number of the infected animals, considering the groups and faecal consistency. All microscopic positive samples were stored at $-20^{\circ} \mathrm{C}$ for further molecular characterization.

\section{Genotype analysis}

Following three cycles of freezing with liquid nitrogen at $196{ }^{\circ} \mathrm{C}(1 \mathrm{~min})$ and thawing at $100^{\circ} \mathrm{C}(5 \mathrm{~min})$, total DNA was extracted from $200 \mathrm{mg}$ of faeces using the QIAamp DNA Stool Mini Kit (QIAGEN, Hilden, Germany) in accordance with the manufacturer's instructions. 
Cryptosporidium species were determined by nested PCR of $\mathrm{a} \approx 830 \mathrm{bp}$ fragment of the SSU rRNA gene and restriction fragment length polymorphism (RFLP) analysis of the secondary PCR products with the endonucleases $S s p \mathrm{I}$, VspI and $M b o I I$, using the same primers and protocol previously described (Xiao et al., 1999, Jiang et al., 2005). Two samples of each Cryptosporidium species identified were sequenced in order to confirm the RFLP results.

Species were assigned by comparing RFLP profiles to those reported by Xiao and Ryan (2008). Subtyping analysis of samples identified as C. parvum and C. ubiquitum at the SSU rRNA locus was performed using a nested PCR followed by sequence analysis of the $60 \mathrm{kDa}$ glycoprotein (gp60) fragment (800-850 bp and $950 \mathrm{bp}$, respectively), as previously described (Alves et al., 2003, Li et al., 2014).

PCR products were purified using Nucleospin Gel and PCR Clean Up (Macherey-Nagel GmbH \& Co. KG, Düren, Germany) and sent to an external sequencing service (Eurofins Genomics, Ebersberg, Germany). The sequences obtained were compared with those on the NCBI database using BLAST (http://www.ncbi.nlm.nih.gov/BLAST/). Cryptosporidium parvum subtypes were named according to the nomenclature described by Sulaiman et al. (2005).

\section{Statistical analysis}

All data were recorded on a spreadsheet (Microsoft Excel@' Microsoft Corp., Redmond, WA) and subsequently processed using MINITAB v. 12.1 (Minitab Inc., State College, PA, USA) and Epi-info 6.04 (CDC, Atlanta, GA, USA). A chisquare test $\left(\chi^{2}\right)$ was used to determine the statistical differences in prevalence rates of Cryptosporidium spp. infection between animal groups and those between animal groups considering faecal consistency. Results were considered statistically significant when $P<0.05$. Odds ratios (OR) were calculated to evaluate the strength of association for Cryptosporidium spp. infection. The existence of significant differences in the average number of oocysts considering faecal consistency and the groups was analysed using the nonparametric Kruskal-Wallis test.

\section{Results}

\section{Microscopic analysis}

Cryptosporidium oocysts were detected in 10.1\% (C195\%: $8.1-12.1$ ) of the animals examined and in $34.4 \%$ (CI95\%: 22.5-46.3) of the farms, in most cases involving only the lamb group (61.9\% of positive farms). Only one positive farm $(4.8 \% ; 1 / 21)$ showed Cryptosporidium oocysts in all animal groups.
The percentage of animals shedding Cryptosporidium oocysts and the MI considering both animal groups and faecal consistency are summarized in Table 1. No samples presented mucus or blood. The prevalence found in pre-weaned lambs was significantly higher than those found in group $2\left(\chi^{2}=\right.$ $14.52 ; P<0.001)$ and group $3\left(\chi^{2}=12.35 ; \mathrm{P}<0.001\right)$. No significant differences were found between ewes belonging to groups 2 and $3\left(\chi^{2}=0.10 ; P=0.719\right)$.

The prevalence of Cryptosporidium spp. decreased with increased faecal consistency and was significantly higher $\left(\chi^{2}=51.854 ; P<0.001\right)$ in diarrhoeic samples than in pasty or normal faeces (Table 1). Most individuals from all animal groups excreted normal or pasty faeces; in contrast, $26.2 \%$ (95\% CI: $21.3-31.1)$ of samples from lambs were diarrhoeic, whereas only $0.5 \%$ (95\% CI: -0.1 to 1.1 ) of ewes were diarrhoeic.

When the possible influence of faecal consistency on the prevalence was analysed in terms of the different animal groups, only significant differences were found in group 1 $\left(\chi^{2}=23.88\right.$; degrees of freedom $\left.(\mathrm{df})=2, P<0.001\right)$ where the probability of finding Cryptosporidium oocysts (OR) in pasty and diarrhoeic faeces was 2.56- and 6.26-fold higher, respectively, than in normal faeces.

The MI was higher in group 1 (18.24 \pm 40.53 standard deviation - SD) than in group $2(14.04 \pm 23.18 \mathrm{SD})$ and group $3(5.51 \pm 7.97 \mathrm{SD})$, but no statistically significant differences $(P>0.05)$ were recorded using the Kruskal-Wallis test (Table 1). In addition, the MI detected in diarrhoeic faeces $(25.23 \pm 51.01 \mathrm{SD})$ was higher than in normal $(12.74 \pm$ 25.22 SD) and pasty $(8.10 \pm 13.25 \mathrm{SD})$ samples (Table 1$)$; however, these differences were not significant using the Kruskal-Wallis test $(P>0.05)$.

\section{Genotype analysis}

Of the 92 Cryptosporidium spp.-positive faecal samples at microscopy, only 15 were successfully genotyped at SSU rRNA because of the small amount of faecal material available and the low parasite loading. These Cryptosporidium isolates were identified as C. parvum (11) and C. ubiquitum (4). Subtyping analysis of $C$. parvum isolates revealed the presence of subtypes IIa15G2R1 and IIdA20G1 and of subtype XIIa for C. ubiquitum. Unfortunately, the subtyping of five C. parvum isolates was not successful. Detailed data are summarized in Table 2.

\section{Discussion}

The present study describes the diffusion and the intensity of Cryptosporidium infection in apparently healthy and in diarrhoeic adult sheep and lambs in Italy. In addition, it updates the knowledge on the epidemiology and molecular 
Table 1 Prevalence and mean intensity (MI) of Cryptosporidium spp. in sheep and lambs from Sardinia (Italy) in terms of animal group and faecal consistency

\begin{tabular}{|c|c|c|c|c|c|c|c|}
\hline & \multicolumn{2}{|l|}{ Group 1} & \multicolumn{2}{|l|}{ Group 2} & \multicolumn{2}{|l|}{ Group 3} & \multirow{2}{*}{$\begin{array}{l}\text { Total } \\
\text { Positive/total } \\
(\%)\end{array}$} \\
\hline & $\begin{array}{l}\text { Positives/ } \\
\text { total } \\
(\%)\end{array}$ & MI (stand. dev.) & $\begin{array}{l}\text { Positives/ } \\
\text { total } \\
(\%)\end{array}$ & MI (stand. dev.) & $\begin{array}{l}\text { Positives/ } \\
\text { total } \\
(\%)\end{array}$ & MI (stand. dev.) & \\
\hline Normal & $10 / 140(7.1)$ & $13.00(29.1)$ & $7 / 154(4.5)$ & $22.29(33.5)$ & $10 / 181(5.5)$ & $5.80(10.9)$ & $27 / 475$ (5.7) \\
\hline Pasty & $14 / 85(16.4)$ & $9.29(16.4)$ & $13 / 150(8.6)$ & $9.26(15.1)$ & $12 / 122(9.8)$ & $5.08(4.9)$ & $39 / 357(10.9)$ \\
\hline Diarrhoeic & $26 / 80(32.5)$ & $25.23(51.0)$ & $0 / 1(0)$ & 0 & $0 / 2(0)$ & 0 & $26 / 83(31.3)$ \\
\hline Total & $50 / 305$ (16.4) & $18.24(40.53)$ & $20 / 305(6.6)$ & $14.04(23.18)$ & $22 / 305(7.2)$ & $5.51(7.97)$ & $92 / 915(10.1)$ \\
\hline
\end{tabular}

identification of Cryptosporidium spp. in sheep farms in Italy since the only previous survey was performed more than 10 years ago and only in lambs (Paoletti et al., 2009).

The overall prevalence of Cryptosporidium infection found in this study $(10.1 \%)$ is higher than that reported in Spain (5.9\%; Díaz et al., 2018a) and lower than most investigations worldwide, which have reported infection rates ranging from 14 to 29\% (Holsback et al., 2018, Mi et al., 2018, Chikweto et al., 2019, Khan et al., 2019). A prevalence higher than 50\% has also been recorded (Bhat et al., 2019). These variations in the prevalence may be due to sample size, geographical region, climate, age of animals, diagnostic methods used, breed, hygiene conditions and management practices (Santin, 2020). In addition, given the low and intermittent oocyst shedding of healthy animals, the sensitivity of microscopical techniques for detecting Cryptosporidium oocysts (ranging from 37.0\% to $90.8 \%$ ) and given that a single sample per animal was analysed in the present study, the percentage of Cryptosporidium-positive lambs and ewes may have been underestimated (Ghoshal et al., 2018, Ahmed and Karanis, 2018).

The prevalence found in lambs (16.4\%) from Sardinia was similar to that recently reported in lambs in Turkey by both microscopic and molecular methods (19.4\%; Kabir et al., 2020) and to that reported by enzyme-linked immunosorbent assay (ELISA) in the only survey carried out on lambs in central Italy (17.45\%; Paoletti et al., 2009). However, these studies used different diagnostic methods used in terms of sensitivity and specificity (Ahmed and Karanis, 2018, Santin, 2020). Nevertheless, the prevalence that we found in lambs is in line with studies performed in Belgium (Geurden et al., 2008) and Algeria (Baroudi et al., 2018), with percentages close to $15 \%$. In contrast, other investigations reported higher prevalence rates in lambs, ranging from 19.4 to $29.5 \%$ (Papanikolopoulou et al., 2018, Khan et al.2019, Kabir et al., 2020, Rabee et al., 2020).

From an epidemiological point of view, it is worth highlighting that in most farms we found Cryptosporidium
Table 2 Species and subtypes of Cryptosporidium spp. identified in the lamb samples examined

\begin{tabular}{lllll}
\hline Id sample & Animal group & Faecal consistency & Species & Subtypes \\
\hline 1 & 1 & Diarrhoeic & C. ubiquitum & XIIa \\
2 & 1 & Pasty & C. ubiquitum & XIIa \\
3 & 1 & Diarrhoeic & C. parvum & FAILED \\
4 & Diarrhoeic & C. parvum & FAILED \\
5 & 1 & Normal & C. parvum & IIaA15G2R1 \\
6 & 1 & Diarrhoeic & C. parvum & IIaA15G2R1 \\
7 & 1 & Diarrhoeic & C. parvum & FAILED \\
8 & 1 & Diarrhoeic & C. parvum & IIaA15G2R1 \\
9 & 1 & Diarrhoeic & C. parvum & IIdA20G1 \\
10 & 1 & Diarrhoeic & C. parvum & FAILED \\
11 & 1 & Diarrhoeic & C. parvum & FAILED \\
12 & 1 & Diarrhoeic & C. parvum & IIaA15G2R1 \\
13 & 1 & Pasty & C. ubiquitum & XIIa \\
14 & 1 & Diarrhoeic & C. parvum & IIaA15G2R1 \\
15 & 1 & Pasty & C. ubiquitum & XIIa \\
\hline
\end{tabular}


oocysts exclusively in the lamb group $(61.9 \%$ of positive farms). Our data revealed that lambs, especially those excreting diarrhoeic faeces, are the most important reservoirs for the protozoan, in line with several other studies (Papanikolopolou et al., 2018, Mammeri et al., 2019, Rabee et al., 2020).

Our data showed that Cryptosporidium prevalence rates decreased with faecal consistency and that the highest percentage and oocyst counts were in diarrhoeic faeces. However, these differences were only statistically significant in preweaned animals where the risk of being positive to Cryptosporidium spp. increased twofold for lambs excreting pasty faeces and more than sixfold for those with diarrhoeic faeces.

These results are in line with many studies that show that cryptosporidial infections are related to neonatal diarrhoea outbreaks in sheep (Muñoz et al., 1996, Quílez et al., 2008, Papanikolopoulou et al., 2018). In contrast, we found that the elimination of diarrhoeic faeces was sporadic in ewes, since only $0.3-0.7 \%$ of adult sheep showed diarrhoea. These results confirm findings that cryptosporidial infections are related to the appearance of diarrhoea outbreaks in neonatal lambs and not in adult sheep (Muñoz et al., 1996, Quílez et al., 2008, Papanikolopoulou et al., 2018; Santin, 2020).

Our results also revealed that the prevalence and MI were higher in lambs than in ewes; in fact young animals seem to be more susceptible to infection than adults (Castro-Hermida et al., 2011, Cacciò et al., 2013, Mi et al., 2018, Santin et al., 2020).

Although the prevalence and MI in sheep before and after parturition were lower than in lambs, adults produce a large volume of faeces and thus may be responsible for environmental contamination with Cryptosporidium oocysts (OrtegaMora et al., 1999, Paraudand Chartier, 2012, Chikweto et al., 2019). In addition, adult sheep presenting low parasite burdens may spread an amount of oocysts below the threshold value of detection shown by microscopy (Ghoshal et al., 2018). Our results thus suggest that ewes in the peripartum period, and especially sheep after parturition since they showed higher MI values, may represent a reservoir of potential pathogenic Cryptosporidium species for lambs (OrtegaMora et al., 1999; Castro-Hermida et al., 2005, 2007; Firoozi et al., 2019). In fact, lambs are weaned 30-40 days after birth in Sardinia, and, therefore, a high risk of maternal transmission of the protozoan to lambs may occur. Sharing the same night shelter and the natural suckling reported in the present survey may contribute to the transmission of Cryptosporidium infection among all animal groups. However, previous studies on domestic ruminants suggest that adults do not play a key role in the transmission of pathogenic species to newborn animals (Fayer et al., 2007; Díaz et al., 2018b). Unfortunately our attempt at molecular identification of the Cryptosporidium species in adult sheep was unsuccessful.
Molecular analysis of faecal specimens positive to microscopy was, however, successful in a few samples, above all in diarrhoeic lambs. Although PCR has been found to be the most sensitive technique for detecting Cryptosporidium infections (Santín et al., 2020), some studies have reported lower infection rates using molecular methods, especially in samples containing a low number of oocysts (Fayer et al., 2007, Mueller-Doblies et al., 2008, Díaz et al., 2010). This is in line with our findings since amplification was only achieved in diarrhoeic samples containing high numbers of oocysts.

The two Cryptosporidium species identified in lambs from Sardinia, C. parvum and C. ubiquitum, are considered the most common species in sheep together with C. xiaoi (Ye et al., 2013, Tzanidakis et al., 2014, Li et al., 2016, Baroudi et al., 2018, Díaz et al., 2018a, Mi et al., 2018, Mammeri et al., 2019, Qi et al., 2019, Rabee et al., 2020, Santín, 2020). Our results are in agreement with most investigations reporting C. parvum as the main species in pre-weaned lambs (CastroHermida et al., 2007, Paoletti et al., 2009, Tzanidakis et al., 2014) and especially in those presenting diarrhoea (MuellerDoblies et al., 2008, Quílez et al., 2008, Díaz et al., 2010, 2015, Papanikolopoulou et al., 2018, Mammeri et al., 2019, Kabir et al., 2020). However, C. parvum has also been commonly found in healthy lambs and even adults (Díaz et al., 2018a, Majeed et al., 2018). Findings from other countries in Europe indicate that C. parvum is also the predominant species in post-weaned and adult sheep (Castro-Hermida et al., 2007, Mueller-Doblies et al., 2008, Díaz et al., 2018a).

Cryptosporidium ubiquitum and C. xiaoi are often the most common species in older animals (Santin, 2020) and are considered as low-pathogenic species (Fayer and Santín, 2009, Fayer et al., 2010) and therefore are mostly reported in apparently healthy sheep (Díaz et al., 2018a, Majeed et al., 2018, Qi et al., 2019). In fact, our results showed the presence of C. ubiquitum in apparently healthy lambs and only in one diarrhoeic lamb in which the diarrhoea may have been caused by an infectious agent not investigated in this study. Since no isolates from ewes were genotyped, this may be the reason why we only found few cases of $C$. ubiquitum and none of C. xiaoi.

The subtyping analysis identified $C$. parvum subtypes belonging to the allelic family IIa, which has already been reported in calves and sheep and is sometimes responsible for human infections (Quílez et al., 2008, Díaz et al., 2010, 2018b, Kabir et al., 2020), as well as IId, previously reported in Europe (Quílez et al., 2008, Papanikolopoulou et al., 2018). In fact, small ruminants are infected exclusively with C. parvum subtypes that belong to the IIa and IId allelic families (Squire et al., 2017). Both C. parvum subtypes IIa and IId have also been found in cattle in Sardinia (Díaz et al., 2018b).

Although in our study there was no close proximity to cattle for any of the sheep farms examined, there may still have been some cross transmission, as has been reported in 
Sardinia for other parasites (Scala et al., 2017). Cryptosporidium ubiquitum subtyping studies are currently very limited; however, the subtype XIIa identified in lambs from Sardinia has been already recognized as the predominant subtype in small ruminants worldwide (Li et al., 2014).

Our findings have public health implications since both the Cryptosporidium species identified are considered zoonotic (Xiao, 2010). C. parvum is considered the second-most common Cryptosporidium species infecting humans (Xiao, 2010). In addition, the $C$. parvum subtype IIaA15G2R1 has been reported to be the most common in humans in Europe (Cacciò and Chalmers, 2016; Feng et al., 2018; Chalmers et al., 2019) and was reported in an AIDS patient in Italy (Del Chierico et al., 2011).

C. ubiquitum is a recognized emerging human pathogen, and the subtype that we found (XIIa) has also been related to human infections (Li et al., 2014). Direct contact with sheep has been reported as one of the most frequent causes of zoonotic transmission, together with the consumption of water contaminated with Cryptosporidium oocysts excreted by sheep (Robertson, 2009, Li et al., 2014; WHO/FAO, 2014). A study carried out in Italy identified diarrhoeic lambs as the source of zoonotic C. parvum for an infant aged 18 months (Cacciò et al., 2013). The risk of zoonotic transmission from sheep is thus higher for those in close contact with sheep, such as farmers and veterinarians.

Our study also highlights the need to establish adequate control and monitoring programs for Cryptosporidium infection in sheep farms, primarily through coprological monitoring in lambs. Currently, the only officially registered drug against cryptosporidiosis in sheep is paromomycin sulphate (Hameed et al., 2019); however, it was only authorized in Italy for trade in 2019 (Gazzetta Ufficiale 2019). The control of environmental contamination should be monitored in association with the control of Cryptosporidium infections on farms, considering the high resistance of Cryptosporidium oocysts in the environment and at normal water treatments (Santin, 2020).

In conclusion, our study revealed that Cryptosporidium is a prevalent and widespread parasite in sheep in Sardinia, which hosts almost $45 \%$ of the entire Italian sheep stock. Pre-weaned lambs, especially those showing diarrhoea, are shedders of zoonotic and pathogenic Cryptosporidium species, and thus, improvements in management and hygiene practices are needed to prevent the transmission of the protozoan. A notable percentage of adult sheep also excreted Cryptosporidium oocysts; however, further research is needed to clarify their role in the epidemiology of human and animal cryptosporidiosis.

Funding Open access funding provided by Università degli Studi di Sassari within the CRUI-CARE Agreement. This research was partially funded by a university research fund ("Fondo di Ateneo per la ricerca
2019”) for Prof. Antonio Varcasia and Prof. Antonio Scala, from the University of Sassari, Italy.

Open Access This article is licensed under a Creative Commons Attribution 4.0 International License, which permits use, sharing, adaptation, distribution and reproduction in any medium or format, as long as you give appropriate credit to the original author(s) and the source, provide a link to the Creative Commons licence, and indicate if changes were made. The images or other third party material in this article are included in the article's Creative Commons licence, unless indicated otherwise in a credit line to the material. If material is not included in the article's Creative Commons licence and your intended use is not permitted by statutory regulation or exceeds the permitted use, you will need to obtain permission directly from the copyright holder. To view a copy of this licence, visit http://creativecommons.org/licenses/by/4.0/.

\section{References}

Ahmed SA, Karanis P (2018) Comparison of current methods used to detect Cryptosporidium oocysts in stools. Int J Hyg Environ Health 221(5):743-763

Alves M, Xiao L, Sulaiman I, Lal AA, Matos O, Antunes F (2003) Subgenotype analysis of Cryptosporidium isolates from humans, cattle, and zoo ruminants in Portugal. J Clin Microbiol 41:2744 2747

Angus KW (1987) Cryptosporidiosis in domestic animals and humans. In Pract 9:47-49

Baroudi D, Hakem A, Adamu H, Amer S, Khelef D, Adjou K, Dahmani H, Chen X, Roellig D, Feng Y, Xiao L (2018) Zoonotic Cryptosporidium species and subtypes in lambs and goat kids in Algeria. Parasit Vectors 11(1):582

Bhat AM, Malik HU, Wani NM, Paul S, Gupta S, Dolma T, Singh SV (2019) First report of Cryptosporidium sp. infection in sheep population of Ladakh. India J Parasit Dis 43(3):513-516

Broglia A, Reckinger S, Cacció SM, Nöckler K (2008) Distribution of Cryptosporidium parvum subtypes in calves in Germany. Vet Parasitol 154(1-2):8-13

Cacciò SM, Sannella AR, Mariano V, Valentini S, Berti F, Tosini F, Pozio E (2013) A rare Cryptosporidium parvum genotype associated with infection of lambs and zoonotic transmission in Italy. Vet Parasitol 191:128-131

Cacciò SM, Chalmers RM (2016) Human cryptosporidiosis in Europe. Clin Microbiol Infect 22(6):471-480

Castro-Hermida J, González-Losada Y, Mezo M, Ares-Mazás E (2002) Study of cryptosporidiosis in a cohort of neonatal calves. Vet Parasitol 106:11-17

Castro-Hermida JA, Delafosse A, Pors I, Ares-Mazás E, Chartier C (2005) Giardia duodenalis and Cryptosporidium parvum infections in adult goats and their implications for neonatal kids. Vet Rec 157(20):623-627

Castro-Hermida JA, García-Presedo I, Almeida A, González-Warleta M, Da Costa JMC, Mezo M (2011) Cryptosporidium spp. and Giardia duodenalis in two areas of Galicia (NW Spain). Sci Total Environ 409(13):2451-2459

Castro-Hermida JA, González-Warleta M, Mezo M (2007) Natural infection by Cryptosporidium parvum and Giardia duodenalis in sheep and goats in Galicia (NW Spain). Small Rumin Res 72(2-3):96-100

Cervone M, Gavazza A, Zbriger A, Mancianti F, Perrucci S (2019) Intestinal parasite infections in dogs affected by multicentric lymphoma and undergoing chemotherapy. Comp Immunol Microbiol Infect Dis 63:81-86

Chalmers RM, Robinson G, Elwin K, Elson R (2019) Analysis of the Cryptosporidium spp. and gp60 subtypes linked to human outbreaks 
of cryptosporidiosis in England and Wales, 2009 to 2017. Parasit Vectors 12(1):95

Chikweto A, Veytsman S, Tiwari K, Cash K, Stratton G, Thomas D, Sharma RN (2019) Prevalence of Cryptosporidium spp. in asymptomatic small ruminants in Grenada, West Indies. Vet Parasitol Reg Stud Reports 15:100262

Del Chierico F, Onori M, di Bella S, Bordi E, Petrosillo N, Menichella D, Cacciò SM, Callea F, Putignani L (2011) Cases of cryptosporidiosis co-infections in AIDS patients: a correlation between clinical presentation and GP60 subgenotype lineages from aged formalin-fixed stool samples. Ann Trop Med Parasitol 105(5):339-349

Díaz P, Navarro E, Prieto A, Pérez-Creo A, Viña M, Díaz-Cao JM, López CM, Panadero R, Fernández G, Díez-Baños P, Morrondo P (2018a) Cryptosporidium species in post-weaned and adult sheep and goats from N.W. Spain: public and animal health significance. Vet Parasitol 254:1-5

Díaz P, Quílez J, Chalmers RM, Panadero R, López C, Sánchez-Acedo C, Morrondo P, Díez-Baños P (2010) Genotype and subtype analysis of Cryptosporidium isolates from calves and lambs in Galicia (NW Spain). Parasitology. 137:1187-1193

Díaz P, Quílez J, Prieto A, Navarro E, Pérez-Creo A, Fernández G, Panadero R, López CM, Díez-Baños P, Morrondo P (2015) Cryptosporidium species and subtype analysis in diarrhoeic preweaned lambs and goat kids from north-western Spain. Parasitol Res 114:4099-4105

Díaz P, Varcasia A, Pipia AP, Tamponi C, Sanna G, Prieto A, Ruiu A, Spissu P, Díez-Baños P, Morrondo P, Scala A (2018b) Molecular characterisation and risk factor analysis of Cryptosporidium spp. in calves from Italy. Parasitol Res 117(10):3081-3090

Fayer R, Santín M (2009) Cryptosporidium xiaoi n. sp. (Apicomplexa: Cryptosporidiidae) in sheep (Ovis aries). Vet Parasitol 164(2-4): 192-200

Fayer R, Santín M, Macarisin D (2010) Cryptosporidium ubiquitum n. sp. in animals and humans. Vet Parasitol 172(1-2):23-32

Fayer R, Santin M, Trout JM (2007) Prevalence of Cryptosporidium species and genotypes in mature dairy cattle on farms in eastern United States compared with younger cattle from the same locations. Vet Parasitol 145(3-4):260-266

Feng Y, Ryan UM, Xiao L (2018) Genetic Diversity and Population Structure of Cryptosporidium. Trends Parasitol 34(11):997-1011

Firoozi Z, Sazmand A, Zahedi A, Astani A, Fattahi-Bafghi A, KianiSalmi N, Ebrahimi B, Dehghani-Tafti A, Ryan U, AkramiMohajeri F (2019) Prevalence and genotyping identification of Cryptosporidium in adult ruminants in central Iran. Parasit Vectors 12(1):510

Food and Agriculture Organization of the United Nations/Worl Health Organization (FAO/WHO) (2014) Multicriteria-based ranking for risk management of food-borne parasites. Microbiolological Risk Assessment Series No. 23. Rome: FAO/WHO. Available from: http://www.fao.org/3/a-i3649e.pdf

Gazzetta Ufficiale Serie Generale (2019) n. 217 del 16/09/2019 (https:// www.gazzettaufficiale.it/eli/id/2019/09/16/19A05638/SG)

Geurden T, Thomas P, Casaert S, Vercruysse J, Claerebout E (2008) Prevalence and molecular characterisation of Cryptosporidium and Giardia in lambs and goat kids in Belgium. Vet Parasitol 155(1-2): $142-145$

Ghoshal U, Jain V, Dey A, Ranjan P (2018) Evaluation of enzyme linked immunosorbent assay for stool antigen detection for the diagnosis of cryptosporidiosis among HIV negative immunocompromised patients in a tertiary care hospital of northern India. J Infect Public Heal 11(1):115-119

Hameed OA, Abu-Zeid TESA, Rasool G, Makki A, Taha MK, Duquesne B (2019) The prevalence of Cryptosporidium Infection in neonatal diarrhoeic sheep lambs with observation of resolution using paromomycin treatment. J Anim Sci Livest Prod 3(2):7
Hatam-Nahavandi K, Ahmadpour E, Carmena D, Spotin A, Bangoura B, Xiao L (2019) Cryptosporidium infections in terrestrial ungulates with focus on livestock: a systematic review and meta-analysis. Parasit Vectors 12(1):453

Holsback L, Lima HE, Vidotto O, Da Silva MA, Patelli THC, Martins FDC, De Seixas M (2018) Cryptosporidium occurrence in ruminants from the North Pioneer mesoregion of Paraná, Brazil. Rev Bras Parasitol Vet 27(2):248-253

Jiang J, Alderisio KA, Xiao L (2005) Distribution of Cryptosporidium genotypes in storm event water samples from three watersheds in New York. Appl Environ Microbiol 71:4446-4454

Kabir MHB, Ceylan O, Ceylan C, Shehata AA, Bando H, Essa MI, Xuan X, Sevinc F, Kato K (2020) Molecular detection of genotypes and subtypes of Cryptosporidium infection in diarrheic calves, lambs, and goat kids from Turkey. Parasitol Int 79:102163

Khan NU, Saleem MH, Durrani AZ, Ahmad N, Hassan A, Shafee M, Khan IU, Khan MA, Zaman S, Khan AU, Ullah N, Razzaq A, Sohail ML (2019) Epidemiology of Cryptosporidium in apparently healthy sheep in Southern Khyber Pakhtunkhwa, Pakistan. J Anim Plant Sci 29(4):912-918

Koinari M, Lymbery AJ, Ryan UM (2014) Cryptosporidium species in sheep and goats from Papua New Guinea. Exp Parasitol 141:134 137

Lanci A, Mariella J, Iacono E, Caffara M, Piva S, Galuppi R, Castagnetti C (2018) Observational study on cryptosporidiosis in an equine perinatology unit. JEquine Vet Sci 71:51-56

Li N, Xiao L, Alderisio K, Elwin K, Cebelinski E, Chalmers R, Santin M, Fayer R, Kvac M, Ryan U, Sak B, Stanko M, Guo Y, Wang L, Zhang L, Cai J, Roelli D, Feng Y (2014, 20) Subtyping Cryptosporidium ubiquitum, a zoonotic pathogen emerging in humans. Emerg Infect Dis (2):217-224

Li P, Cai J, Cai M, Wu W, Li C, Lei M, Xu H, Feng L, Ma J, Feng Y, Xiao L (2016) Distribution of Cryptosporidium species in Tibetan sheep and yaks in Qinghai. China Vet Parasitol 15:58-62

Majeed QAH, El-Azazy OME, Abdou NMI, Al-Aal ZA, El-Kabbany AI, Tahrani LMA, AlAzemi MS, Wang Y, Feng Y, Xiao L (2018) Epidemiological observations on cryptosporidiosis and molecular characterization of Cryptosporidium spp. in sheep and goats in Kuwait. Parasitol. Res. 117(5):1631-1636

Mammeri M, Cartou L, Chevillot A, Thomas M, Julien C, Vallée I, Polack B, Follet J, Adjou KT (2019) First identification of Cryptosporidium parvum zoonotic subtype IIaA15G2R1 in diarrheal lambs in France. Vet Parasitol Reg Stud Reports 18:100355

Mi R, Wang X, Huang Y, Mu G, Zhang Y, Jia H, Zhang X, Yang H, Wang X, Han X, Chen Z (2018) Sheep as a potential source of zoonotic cryptosporidiosis in China. Appl Environ Microbiol 84(18): $00868-\mathrm{e} 00818$

Mueller-Doblies D, Giles M, Elwin K, Smith RP, Clifton-Hadley FA, Chalmers RM (2008) Distribution of Cryptosporidium species in sheep in the UK. Vet Parasitol 154(3-4):214-219

Muñoz M, Alvarez M, Lanza I, Cármenes P (1996) Role of enteric pathogens in the aetiology of neonatal diarrhoea in lambs and goat kids in Spain. Epidemiol Infect 117(1):203-211

Ortega-Mora LM, Requejo-Fernández JA, Pilar-Izquierdo M, PereiraBueno J (1999) Role of adult sheep in transmission of infection by Cryptosporidium parvum to lambs: confirmation of periparturient rise. Int J Parasitol 29(8):1261-1268

Paoletti B, Giangaspero A, Gatti A, Iorio R, Cembalo D, Milillo P, Traversa D (2009) Immunoenzymatic analysis and genetic detection of Cryptosporidium parvum in lambs from Italy. Exp Parasitol 122: 349-352

Papanikolopoulou V, Baroudi D, Guo Y, Wang Y, Papadopoulos E, Lafi SQ, Abd El-Tawab MM, Diakou A, Giadinis ND, Feng Y, Xiao L (2018) Genotypes and subtypes of Cryptosporidium spp. in diarrheic lambs and goat kids in northern Greece. Parasitol Int 67(4):472475 
Paraud C, Chartier C (2012) Cryptosporidiosis in small ruminants. Small Rumin Res 103(1):93-97

Pritchard GC, Marshall JA, Giles M, Mueller-Doblies D, Sayers AR, Marshall RN, Elwin K, Chalmers RM (2008) Cryptosporidium species in lambs submitted for diagnostic postmortem examination in England and Wales. Vet Rec 163(23):688-689

Qi M, Zhang Z, Zhao A, Jing B, Guan G, Luo J, Zhang L (2019) Distribution and molecular characterization of Cryptosporidium spp., Giardia duodenalis, and Enterocytozoon bieneusi amongst grazing adult sheep in Xinjiang. ChinaParasitol Int 71:80-86

Quílez J, Torres E, Chalmers RM, Hadfield SJ, Del Cacho E, SánchezAcedo C (2008) Cryptosporidium genotypes and subtypes in lambs and goat kids in Spain. Appl Environ Microbiol 74(19):6026-6031

Rabee AH, Merza AD, Al-Hasnawy MH (2020) Detection of parasites causing diarrhoea in lambs of Babylon governorate. Iraq Plant Arch $20: 1528-1532$

Robertson LJ (2009) Giardia and Cryptosporidium infections in sheep and goats: a review of the potential for transmission to humans via environmental contamination. Epidemiol Infect 137(7):913-921

Roellig DM, Xiao L (2020) Cryptosporidium genotyping for epidemiologytracking. Methods Mol Biol 2052:103-116

Ryan UM, Bath C, Robertson I, Read C, Elliot A, McInnes L, Traub R, Besier B (2005) Sheep may not be an important zoonotic reservoir for Cryptosporidium and Giardia parasites. Appl Environ Microbiol 71(9):4992-4997

Ryan U, Fayer R, Xiao L (2014) Cryptosporidium species in humans and animals: current understanding and research needs. Parasitology 141(13):1667-1685

Ryan U, Zahedi A, Paparini A (2016) Cryptosporidium in humans and animals - a one health approach to prophylaxis. Parasite Immunol 38(9):535-547

Santin M (2020) Cryptosporidium and Giardia in ruminants. Vet Clin N AmFood Animal Practice 36(1):223-238

Sauda F, Malandrucco L, De Liberato C, Perrucci S (2019) Gastrointestinal parasites in shelter cats of central Italy. Vet Parasitol Reg Stud Reports 18:100321

Scala A, Bosco A, Pipia AP, Tamponi C, Musella V, Costanzo N, Testoni F, Montisci A, Mocci G, Longhi A, Tilocca L, Rinaldi L, Cringoli G, Varcasia A (2017) Cystic echinococcosis in cattle dairy farms: spatial distribution and epidemiological dynamics. Geospat Health 12(1):562

Squire SA, Yang R, Robertson I, Ayi I, Ryan U (2017) Molecular characterization of Cryptosporidium and Giardia in farmers and their ruminant livestock from the coastal Savannah zone of Ghana. Infect Genet Evol 55:236-243

Sulaiman IM, Hira PR, Zhou L, Al-Ali FM, Al-Shelahi FA, Shweiki HM, Iqbal J, Khalid N, Xiao L (2005) Unique endemicity of cryptosporidiosis in children in Kuwait. J Clin Microbiol 43:2805-2809

Tzanidakis N, Sotiraki S, Claerebout E, Ehsan A, Voutzourakis N, Kostopoulou D, Stijn C, Vercruysse J, Geurden T (2014) Occurrence and molecular characterization of Giardia duodenalis and Cryptosporidium spp. in sheep and goats reared under dairy husbandry systems in Greece. Parasite 21:45

Varcasia A, Dessì G, Lattanzio S, Marongiu D, Cuccuru C, Carta S, Meloni MP, Tamponi C, Scala A (2020) Cystic echinococcosis in the endemic island of Sardinia (Italy): has something changed? Parasitol Res 119:2207-2215

Xiao L (2010) Molecular epidemiology of Cryptosporidiosis: an update. Exp Parasitol 124:80-89

Xiao, L., Ryan, U.M., 2008. Molecular epidemiology. In: Fayer, R., Xiao, L. (Eds.), Cryptosporidium and Cryptosporidiosis, 2nd ed. CRC Press, Boca Raton, pp. 119-172.

Xiao L, Morgan UM, Limor J, Escalante A, Arrowood M, Shulaw W, Thompson RCA, Fayer R, Lal AA (1999) Genetic diversity within Cryptosporidium parvum and related Cryptosporidium species. Appl Environ Microbiol 65:3386-3391

Ye J, Xiao L, Wang Y, Wang L, Amer S, Roellig DM, Guo Y, Feng Y (2013) Periparturient transmission of Cryptosporidium xiaoi from ewes to lambs. Vet.Parasitol. 197(3-4):627-633

Zhang X, Jian Y, Li X, Ma L, Karanis G, Qigang C, Karanis P (2018) Molecular detection and prevalence of Cryptosporidium spp. infections in two types of domestic farm animals in the Qinghai-Tibetan plateau area (QTPA) in China. Parasitol Res 117:233-239

Publisher's note Springer Nature remains neutral with regard to jurisdictional claims in published maps and institutional affiliations. 